\title{
The genus Diplectrona Westwood (Trichoptera: Hydropsychidae) in the Japanese main islands
}

\author{
TAKAO NOZAKI \\ 3-16-15, Midorigaoka, Ninomiya-machi, Naka-gun, Kanagawa, 259-0132 Japan. \\ "'takao.nozaki@nifty.com; ㅇhttps://orcid.org/0000-0001-6492-6513
}

\begin{abstract}
The genus Diplectrona Westwood (Trichoptera: Hydropsychidae) is revised for the Japanese main islands, and four species are recognized, the three species D. aiensis Kobayashi, D. burha Schmid, and D. kibuneana Tsuda, and one new species, D. takaii sp. nov. Diplectrona difficultata (Kobayashi) is synonymized with D. kibuneana. Diplectrona japonica Banks and D. albomarginata Ulmer are transferred to the genus Homoplectra Ross.
\end{abstract}

Key words: caddisfly, description, new species, new synonym, new combination, Homoplectra

\section{Introduction}

The genus Diplectrona Westwood 1839 is a large genus composed of 149 species found in all biogeographic regions except for Antarctica (Sun 2017; Malicky 2020; Malicky \& Mey 2020; Oláh et al. 2020; Morse 2021). Ulmer (1907) recognized the first Japanese Diplectrona species, D. japonica (Banks 1906), which was originally described as a member of the genus Arctopsyche McLachlan 1868 from Kyushu, one of four main islands in Japan. He described a second species, D. albomarginata Ulmer 1907, from central Honshu, the largest island in Japan. Subsequently, three species have been described within this genus from Honshu: D. kibuneana Tsuda 1940, D. tohokuensis Kobayashi 1973, and D. aiensis Kobayashi 1987; although D. tohokuensis was transferred later to the genus Homolectra Ross 1938 by Nozaki (2019). A final species, Hydropsyche difficultata Kobayashi 1984, described from Honshu, was transferred to the genus Diplectrona by Nozaki (1997).

Recently, Ito \& Nozaki (2018) studied the hydropsychid species of the Ryukyu Archipelago, southwestern Japan, and added to the known fauna three Diplectrona species: D. albofasciata (Ulmer 1913), D. burha Schmid 1961, and D. uken Ito \& Nozaki 2018. However, some taxonomic problems remain in the main islands. For example, Banks (1906) provided only general characteristics of D. japonica; in particular, distinct yellow markings on the forewings, whereas multiple species having this character were found from central Honshu (Kawase \& Morita 2014). Nozaki (2016) emphasized the necessity to study not only the specific status but also the generic arrangement of this species. The description of D. albomarginata was based on a single female specimen (Ulmer 1907), which is insufficient for specific identification. Furthermore, several authors recorded unnamed 'species' from Honshu (e.g., Kagaya et al. 1998; Kawase \& Morita 2010; Nojima 2017).

To solve these taxonomic problems, I examined specimens collected from the Japanese main islands including the type specimens of $D$. japonica, $D$. albomarginata, $D$. difficultata, and $D$. aiensis, and recognized only four species. In this paper, I describe or redescribe males and females of these four species, and transfer D. japonica and $D$. albomarginata to the genus Homoplectra.

\section{Material and methods}

Association of males and females was based on the presence of similar general body characters, i.e., color, size, and 
shape of setal warts on the head, when they were collected together multiple times. Male and female genitalia were figured after being cleared in a $10 \%$ solution of $\mathrm{KOH}$. Morphological terms used in this study are indicated in the figure legends and comply with those of Schmid (1998), Oláh \& Johanson (2008), and Ito \& Nozaki (2018).

Depositories of specimens used in this study are abbreviated as follows: Natural History Museum and Institute, Chiba (CBM-ZI); Kanagawa Prefectural Museum of Natural History (KPM-NK); Minakuchi Kodomo-no-mori Nature Center (MITR); Museum of Natural and Environmental History, Shizuoka (SPMN-IS); and personal collections of T. Ito (TI), N. Kawase (NK), N. Kuhara (KuN), K. Nojima (KN), M. Tanaka (MT), and T. Torii (TT). Other specimens are deposited in the personal collection of the author (no indication).

\section{Species descriptions}

\section{Diplectrona kibuneana Tsuda 1940}

(Figs 1,7)

Diplectrona kibuneana Tsuda 1940, 24-25, male; Inazu \& Nishida 2011, 191, male, larva; Nozaki 2016, 75, 348, male; Tanaka 2016, 2, 5, male; Park et al. 2017, 5-6, male; Tanida 2018, 571, 577, larva.

Diplectrona sp. DB: Akagi 1956, 24-25, larva; Tsuda \& Akagi 1962, 133-134, larva; Tanida 1985, 176-177, larva. Hydropsyche difficultata Kobayashi 1984, 5-6, male. New synonym.

Diagnosis. The male of this species is similar to that of D. burha distributed in southeastern Asia and Japan in genitalic morphology, but is easily distinguishable from the latter by the pair of long lateral filament of the abdominal segment V, and the pair of large internal gland of the segment VIII: Each lateral filament is approximately 2 times as long as segment $\mathrm{V}$ in this species, but is about 1.3 times as long as the segment in $D$. burha; and each internal gland is longer than the segment VII in this species, but is lacking in D. burha.

Adult (Figs 1A-1L). Head and body (Fig. 1A) mostly dark brown, antennae with dark stripes; forewings black, with sparse white spots, spots around pterostigma larger (Fig. 1A), but indistinct for specimens preserved in alcohol. Head (Fig. 1B) with small round frontal setal wart (f.s.w.) and pairs of anterior and posterior setal warts; each anterior setal wart (a.s.w.) semicircular, mesal margin slightly concave; each posterior setal wart (p.s.w.) large, oval. Venation as in Figure 1C; forewings each $6.0-8.5 \mathrm{~mm}$ long in male $(\mathrm{n}=10), 6.8-10.5 \mathrm{~mm}$ in female $(\mathrm{n}=10)$, with postcostal region (posterior of looped anal veins) half as long as wing and wider than any wing cells; hind wings each with Sc and R1 veins bowed at pterostigma. Pair of lateral filaments (1.f.) of abdominal segment V (V) long, each approximately 2 times as long as segment V in male (Fig. 1D), 1.5 times in female. Segment V with small internal gland (i.g.) both in male and female. Segment VIII (VIII) with very large internal gland in male, apparently longer than segment VII (VII) (Fig. 1D), lacking in female.

Male genitalia (Figs 1E-1I). Segment IX (IX) triangular in lateral aspect (Fig. 1E). Segment X (X) with pair of mesocaudal lobes (m.c.l.), separated apically in dorsal aspect (Fig. 1F), each with round apex in dorsal and lateral aspects (Figs 1E, 1F), with stout clavate setae; pair of lateral lobes (1.1.) projected outward in dorsal aspect (Fig. 1F), appearing jagged posteriorly because of tiny marginal spines, with short stout setae ventrally, shape of posterior margin in lateral aspect variable (Figs 1E, 1I); pair of preanal appendages (p.a.) large oval in lateral aspect (Fig. 1E), weakly bulging, setose. Inferior appendages (i.a.) each with basal segment long, extending beyond apex of segment $X$, gradually thickened from base to apex; distal segment about $1 / 3$ as long as basal segment, tapering to apex, curved mesad (Fig. 1F). Phallic apparatus thick basally, narrow in middle (Fig. 1G); apex weakly bulging laterally in dorsal aspect (Fig. 1H), with two pairs of endothecal processes (e.p.) dorsally, each process ovate, dorsal pair larger than ventral pair.

Female genitalia (Figs 1J-1L). Sternum VIII cleft from base, forming pair of lateral lobes (1.1.) widely separated from each other posteriorly in ventral aspect (Fig. 1L). Segment IX (IX) triangular in dorsal aspect (Fig. 1K), rhomboid in lateral aspect (Fig. 1J); with pair of long external sclerotized ribs (s.r.) ventrolaterally, weakly ridged (Figs 1J, 1L). Vulval scale (v.s.) tongue-like in ventral aspect (Fig. 1L), reinforced by sclerotized ribs basolaterally; apex membranous with small median bulge. Segment X (X) rhomboid in lateral aspect (Fig. 1J), anteroventral corner slightly protruding anteriorly.

Immature stage. Diplectrona sp. DB described by Akagi (1956) is the larval stage of this species (Kagaya et al. 1998; Inazu \& Nishida 2011). 

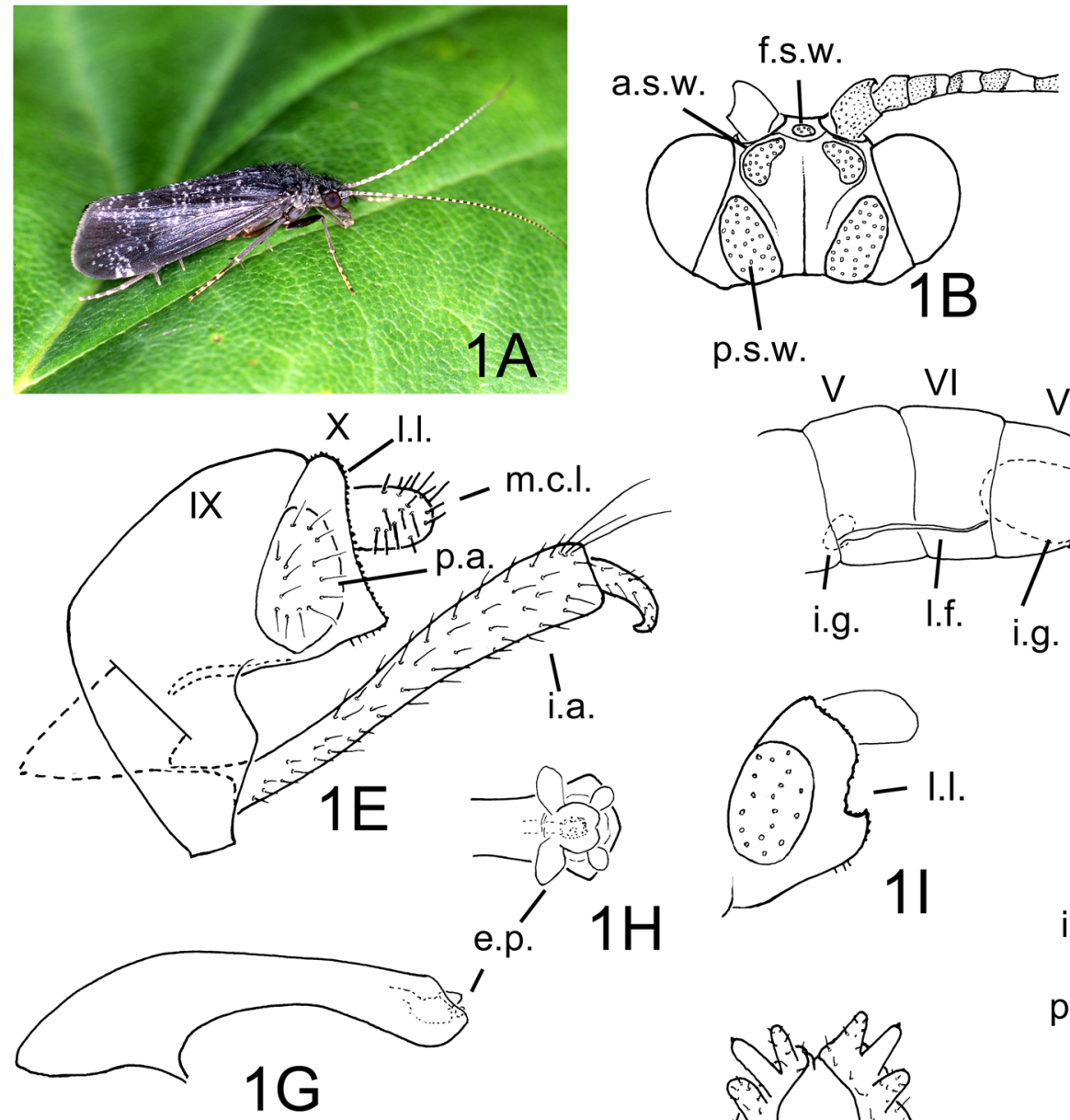

p.S.W.

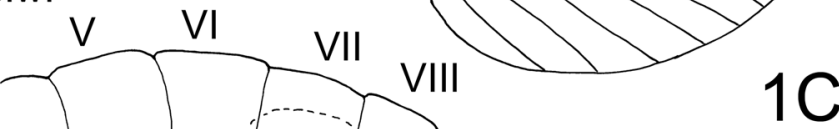

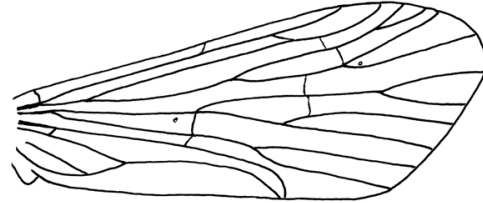

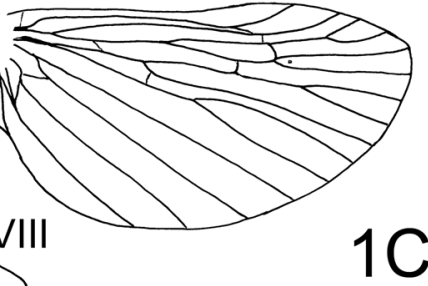

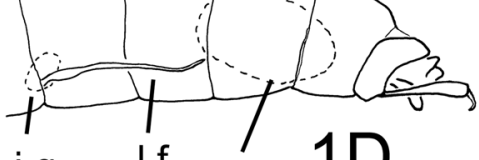

i.g.

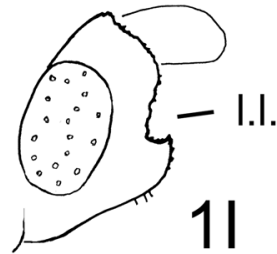

i.g.

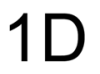

i.a.

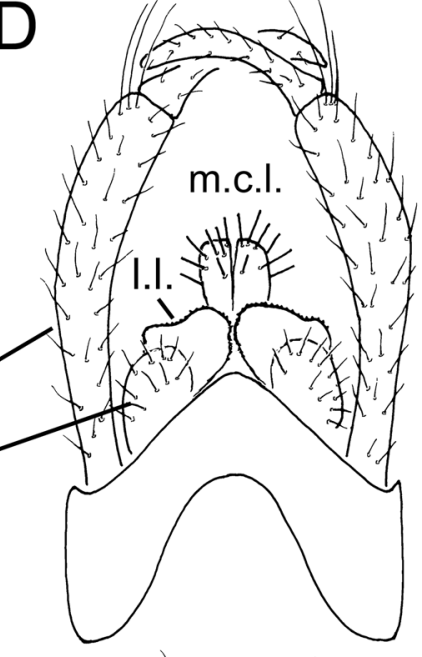

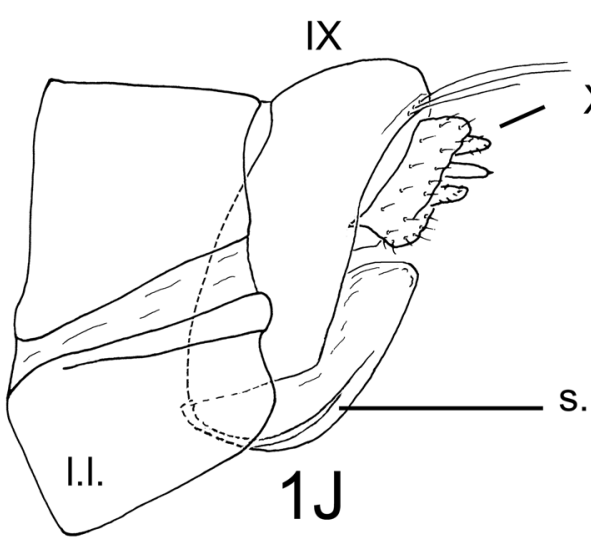
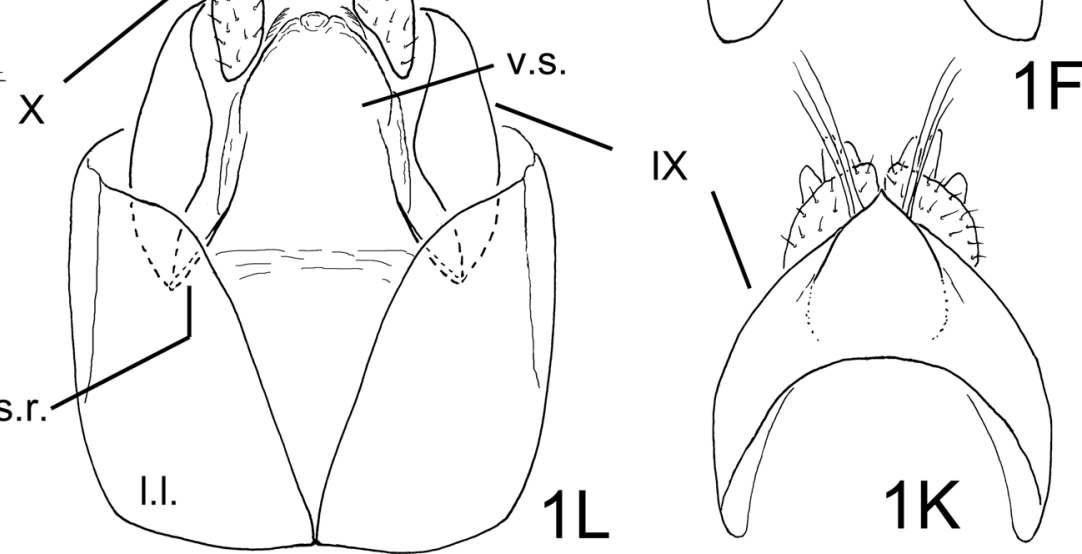

FIGURE 1. Diplectrona kibuneana Tsuda 1940. 1A-1I, male: 1A, habitus (Kochi, photographed by M. Takai), right lateral; 1B, head, dorsal; 1C, right wings, dorsal; 1D, abdominal segments $\mathrm{V}-\mathrm{X}$, left lateral; 1E, genitalia, left lateral; 1F, same, dorsal; $1 \mathrm{G}$, phallic apparatus, left lateral; $1 \mathrm{H}$, same, apical part, dorsal; 1I, segment X, left lateral, type series male of Hydropsyche difficultata Kobayashi. 1J-1L, female genitalia: 1J, left lateral; 1K, dorsal; 1L, ventral. Abbreviations: a.s.w. = anterior setal wart (paired), e.p. $=$ endothecal process $($ paired), f.s.w. $=$ frontal setal wart, i.a. $=$ inferior appendage $($ paired), i.g. $=$ internal gland (paired) of segment V or VIII, m.c.l. = mesocaudal lobe of segment X (paired), 1.f. = lateral filament (paired), 1.1. = lateral lobe of segment VIII in female or X in male (paired), p.a. = preanal appendage of segment X (paired), p.s.w. = posterior setal wart (paired), s.r. = sclerotized rib (paired), $\mathrm{V}-\mathrm{X}=$ abdominal segments $\mathrm{V}-\mathrm{X}$, v.s. = vulval scale.

Specimens examined. Holotype male, paratype male of Hydropsyche difficultata Kobayashi 1984 (in alcohol): Konomazawa, Aone, Tsukui-machi, Kanagawa, 13.vii.1983, M. Kobayashi (KPM-NK). Hokkaido: 1 female, Akanko-Takiguchi, Akan-cho, Kushiro-shi, 1.vii.1991, Y. Hirama; 4 males, 2 females, Ken'ichi River, Yakumocho, 26.vi.-20.vii.1995, Y. Ito \& T. Ito (TI). Honshu, Iwate, 1 female, Omori, Koromogawa-ku, Oshu-shi, 19- 
20.vi.2017, T. Ito. Akita: 1 male, Otaki-yama, Akita-shi, 6.vii.2004, M. Tanaka (MT); 1 female, Kasukose, Sannai, Yokote-shi, 30.viii.2011, M. Tanaka. Fukushima: 5 males, 2 females, Shio-zawa, Kanozu, Tadami-machi, alt. 430 m, 2-3.viii.2014, S. Inaba. Gunma: 1 male, Funako, Kanna-machi, 28.vii.1998, T. Hattori (SPMN-IS). Ibaraki: 1 male, Uwaso, Ishioka-shi, 4.vi.2011, N. Katsuma. Tokyo: 1 male, Una-zawa, Okutama-machi, 10.vii.1991, T. Nozaki; 4 males, 1 female, Mitsu-sawa, Hinode-machi, 9.vii.1991, T. Nozaki \& T. Kagaya; 5 males, Takimoto-sawa, Oguno, Hinode-machi, alt. 430 m, 21.vii.2010, T. Nozaki. Kanagawa: 2 males, Sawai-gawa, Fujino, Midori-ku, Sagamihara-shi, 11.vii.1984, T. Nozaki; 2 males, 2 females, Sakai-gawa, Shiroyama-cho, Sagamihara-shi, larvae collected on 7.vi.1984, adults emerged on 9.vii-12.viii.1984, T. Nozaki; 7 males, Jindai-sawa, Yamakita-machi, 5.vii.1984, T. Nozaki. Niigata: Higashimata-gawa, Oishi, Sekikawa-mura, 31.viii-1.ix.2014, S. Inaba. Toyama: 1 female, Kotani-gawa, Nanto-shi, alt. 450 m, 30.vii.1995, T. Hattori (SPMN-IS). Yamanashi: 1 male, Akasawa, Hayakawa-cho, 3.viii.2008, T. Nozaki. Nagano: 1 male, Shira-kawa, Mitake, Kiso-machi, alt. 1060 m, 4.viii.1998, T. Nozaki; 1 male, Oonagare-sawa, Tohyama-gawai, Iida-shi, 8.viii.2008, T. Torii (TT). Gifu: 1 male, Tsukechikyo, Nakatsugawa-shi, 22.viii.2008, T. Torii (TT); 1 female, Ten-no-taki, Mikawa, Shirakawa-cho, 12.vi.2010, T. Nozaki. Shizuoka: 1 male, 1 female, Jizodo-gawa, Izu-shi, 2.vi.2009, T. Hattori (SPMN-IS); 3 males, same locality, 16.ix.2009 (SPMN-IS); 1 male, 1 female, Kurobe-sawa, Hirano, Aoi-ku, Shizuoka-shi, 20.viii.2009, T. Hattori (SPMN-IS); 1 male, 1 female, Hirano, Aoi-ku, Shizuoka-shi, 25.v.1995, T. Hattori (SPMN-IS). Mie: 1 male, Yunoyama, Komono-cho, 30.v.1997, H. Morita; 2 males, Minamiise-cho, 2.x.2008, H. Morita (NK); 3 males, Kakiuchi, Hakusan-cho, Tsu-shi, 31.v.2009, H. Morita (NK); 1 male, Hirakura, Misugi-cho, Tsu-shi, 14.viii.2011, H. Morita (NK); 3 males, Kammuri-yama, Mizusawa-cho, Yokkaichi-shi, 6-16.iv.2009, H. Morita (NK); 6 males, Kikaji, Iitaka-cho, Matsusaka-shi, 4.viii.2019, H. Morita (NK). Shiga: 2 males, 2 females, Yuzurio, Eigenji-cho, Higashi-omi-shi, alt. 380 m, 6.ix.2013, T. Ito. Hyogo: 3 males, Omen-no-taki, Shinonsen-cho, 12.viii.1989, C. Kugo. Hiroshima: 1 male, Ohta-gawa, Doi, Akiota-cho, 26.vii.2003, S. Nakamura; 1 male, 1 femal, Hosomi-dani, Yoshiwa, Hatsukaichi-shi, alt. 820 m, 19.vii-13.ix.2005, I. Mori. Shikoku, Ehime: 1 male, Ono-ga-hara, Seiyoshi, 7.viii.2018, E. Yamamoto; 2 males, 3 females, Izugatani-yama, Nishidani, Kumakogen-cho, 1-10.viii.2018, E. Yamamoto; 7 males, 6 females, Honomata, Odamiyama, Nakagawa, Uchiko-cho, 11.ix.2018, E. Yamamoto; 10 males, 2 females, Namakusa-dani, Odamiyama, Nakagawa, Uchiko-cho, 16.vii.2000, E. Yamamoto; 1 male, 1 female, same locality, 11-20.vii.2020, E. Yamamoto. Kochi: 1 male, Yosakoi-toge, Teragawa, Ino-cho, 3.viii.2000, I. Yamashita; 1 male, Kuwaze, Ino-cho, alt. 618 m, 2.vii.2003, K. Nio; 2 males, Befu-kyo, Monobe-cho, Kami-shi, 18.ix.2003, K. Nio; 1 male, Tengu-ike, Tsuno-cho, 13.viii.2005, M. Takai; 1 male, 1 female, Kuishi-yama, Kochishi, 8.vii.2005, M. Takai; 1 male, Kitao, Hane, Muroto-shi, 3.vi.2006, M. Takai; 2 males, Kanaezaki, Tosashimizushi, 30.ix.2006, M. Takai; 2 males, 2 females, near Ashizuri-misaki, Tosashimizu-shi, 21.v.1999, A. Ohkawa \& T. Ito. Kyushu, Fukuoka: 1 male, Mt. Hiko, Soeda-machi, alt. 650 m, 10.ix.1996, T. Nozaki. Nagasaki: 4 males, 3 females, Todoroki-keikoku, Takaki-cho, Isahaya-shi, 18.ix.2000, T. Nozaki. Kumamoto: 2 males, Kakizako, Izumi-machi, Yatsushiro-shi, 24.v.1998, T. Hattori (SPMN-IS). Miyazaki: 3 males, 2 females, Kawanaka, Aya-cho, 9.xi.2012, Y. Hayashi. Kagoshima: 2 males, 2 females, Tashirofumoto, Kinko-cho, 28.vi.2014, S. Inaba.

Distribution. Japan: Hokkaido, Honshu, Shikoku, Kyushu, Tsushima, Yaku-shima. South Korea.

Japanese name. Kibune-miyama-shima-tobikera.

Remarks. Tsuda (1940) described this species based on two males collected from Kyoto, central Japan. Although I could not examine the type series materials of this species, which are likely lost, the male characteristics in the original description agree well with those of the male described above, especially the length of lateral filaments of abdominal segment $\mathrm{V}$, and the shapes of mesocaudal lobes of segment $\mathrm{X}$ and inferior appendages. After comparative study of the type series males of Hydropsyche difficultata with specimens collected widely from Japanese main islands, I recognized that $H$. difficultata is the same species as $D$. kibuneana. Although the posterior margin of each lateral lobe of $H$. difficultata bears a ventral projection directed posterodorsad in lateral aspect (Kobayashi 1984, fig. 12; Fig. 1I), the shape is variable in D. kibuneana even in the same locality.

In the collection of the late Mr. Kobayashi deposited in the Kanagawa Prefectural Museum of Natural History, the holotype and paratype males of $H$. difficultata were preserved together in the same vial with two handwritten labels reading "7262 3 ." A male without abdomen and a cleared abdomen in the vial must have been used in the original description by Kobayashi (1984). I added a label "HOLOTYPE labeled by T. Nozaki, 2021" into this vial and another male was moved into a different small vial with labels, "7262 ${ }^{\lambda}$ " and "PARATYPE labeled by T. Nozaki, 2021." 


\section{Diplectrona burha Schmid 1961}

(Figs 2,7)

Diplectrona burha Schmid 1961, 200-201, pl. 17, male; Malicky 2002, 1205-1206, 1218, 1233, male; Ito \& Nozaki 2018, 547-548, male, female.

Diagnosis. The male of this species is similar to that of D. kibuneana in the genitalic morphology but is distinguishable from that of the latter by the characters given in the diagnosis for that species.

Adult (Figs 2A-2G). Only one male specimen available in this study. General appearance similar to D. kibuneana, but white markings more distinct (Fig. 2A). On the head (Fig. 2B), frontal setal wart (f.s.w.) small oval; each anterior setal wart (a.s.w.) divided into 2 warts, anterior one [= vertexal lateroantennal complex setal wart of Sun (2017)] small, long oval, posterior one [= vertexal lateral compact setal wart of Sun (2017)] irregularly triangular; each posterior setal wart (p.s.w.) large oval. Forewings each $7.0 \mathrm{~mm}$ long, venation similar to that of D. kibuneana (Fig. 1C). Pair of lateral filaments (l.f.) of abdominal segment V (V) long, each about 1.3 times as long as segment $\mathrm{V}$ (Fig. 2C). Internal gland of segment V small, internal gland of segment VIII (VIII) absent (Fig. 2C).

Male genitalia (Figs 2D-2G). Segment IX (IX) triangular in lateral aspect (Fig. 2D). Segment X (X) with pair of mesocaudal lobes (m.c.l.), each long oval in lateral and dorsal aspects (Figs 2D, 2E), with stout clavate setae; pair of lateral lobes (1.1) projecting outward in dorsal aspect (Fig. 2E), with spine-like posterodorsal projection, ventral margin strongly sclerotized, with short setae; pair of preanal appendages large oval in lateral aspect, weakly bulging, setose. Inferior appendages (i.a.) each with basal segment long club-like, extending beyond apex of segment $\mathrm{X}$ (Fig. 2D); distal segment about $1 / 3$ as long as basal segment, tapering to apex, curved mesad (Fig. 2E). Phallic apparatus narrow in middle in lateral aspect (Fig. 2F); with two pairs of endothecal processes (e.p.) apicodorsally, each ovate (Fig. 2G).
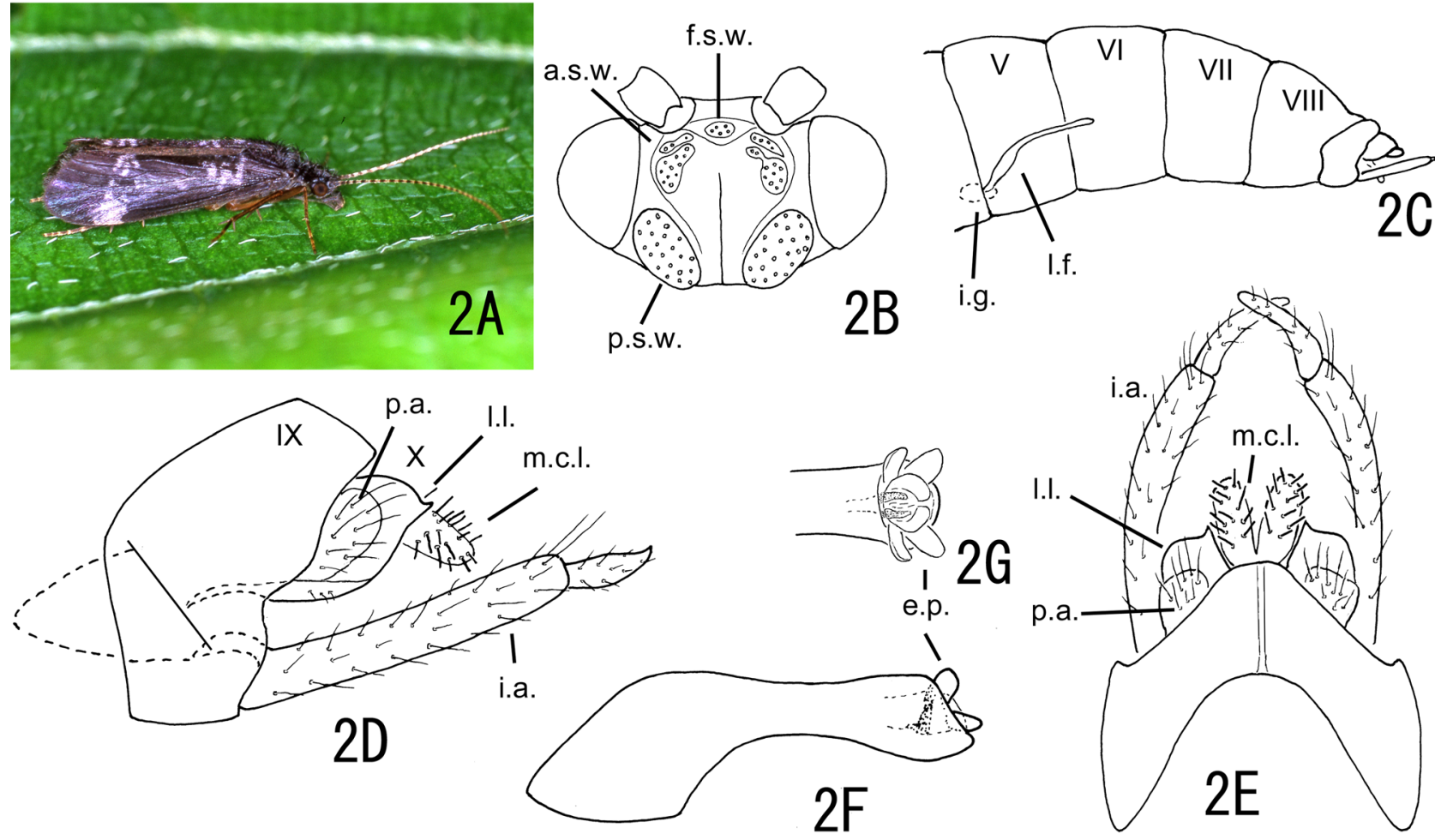

FIGURE 2. Diplectrona burha Schmid 1961.2A-2G, male: 2A, habitus (Kochi, photographed by M. Takai), right lateral; 2B, head dorsal; 2C, abdominal segments V-X, left lateral; 2D, genitalia, left lateral; 2E, same, dorsal; 2F, phallic apparatus, left lateral; 2G, same, apical part, dorsal. Abbreviations: a.s.w. = anterior setal wart (paired), e.p. = endothecal process (paired), f.s.w. $=$ frontal setal wart, i.a. $=$ inferior appendage (paired), i.g. $=$ internal gland (paired) of segment V, m.c.l. = mesocaudal lobe of segment X (paired), 1.f. = lateral filament (paired), 1.1. = lateral lobe of segment X (paired), p.a. = preanal appendage of segment $\mathrm{X}($ paired), p.s.w. = posterior setal wart (paired), $\mathrm{V}-\mathrm{X}=$ abdominal segments $\mathrm{V}-\mathrm{X}$. 
Immature stage. Unknown.

Specimens examined. Shikoku, Kochi: 1 male, Befu, Monobe-cho, Kami-shi, 27.vii.2003, M. Takai.

Distribution. Japan (Shikoku, Ryukyu islands), Pakistan, India, Nepal, Thailand, Vietnam, Taiwan.

Japanese name. Buruha-miyama-shima-tobikera.

Remarks. The single male specimen available in this study has many characteristics which agree with those of D. burha described or redescribed by Schmid (1961), Malicky (2002), and Ito \& Nozaki (2018); for example, the length of the lateral filaments of abdominal segment $\mathrm{V}$, the size of the internal glands of segment $\mathrm{V}$, lack of internal glands of segment VIII, and the shape of the genitalia. The shape of the mesocaudal lobes and lateral lobes of the segment $\mathrm{X}$ are different from those of males collected from Ryukyu islands, southwestern Japan (Ito \& Nozaki 2018), but similar to those illustrated in the original description (Schmid 1961, pl. 17, figs 7, 8). Schmid (1961) and Malicky (2002) reported variations of the male genitalia in this species.

\section{Diplectrona aiensis Kobayashi 1987}

(Figs 3, 7)

Diplectrona aiensis Kobayashi 1987, 19, 32, male; Morita 2013, 62-63; Nozaki 2016, 348, male; Tanaka 2016, 2, 5, male.

Diagnosis. Male genitalia of this species are similar to those of Diplectrona guangxiensis Sun 2017 described from China but are distinguished by the length of the lateral filaments of the abdominal segment V: Each lateral filament is about 1.7 times longer than the segment $\mathrm{V}$ in $D$. aiensis, but slightly shorter than the segment in D. guangxiensis. Furthermore, the pair of internal glands of the abdominal segment VIII of $D$. aiensis are larger than those of $D$. guangxiensis.

Adult (Figs 3A-3J). General appearance similar to D. kibuneana (Fig. 3A). On head (Fig. 3B), frontal setal wart (f.s.w.) small oval; each anterior setal wart (a.s.w.) divided into 3 warts, 2 anterior ones each small oval, posterior one triangular; each posterior setal wart (p.s.w.) large oval. Forewings each 7.0-9.5 mm long in male ( $\mathrm{n}=10)$, 9.3-11.5 mm in female $(\mathrm{n}=10)$, venation similar to that of D. kibuneana (Fig. 1C). Pair of lateral filaments (1.f.) of abdominal segment V (V) long, each about 1.7 times as long as segment V in male (Fig. 3C), 1.4 times in female. Segment V with small internal gland (i.g.) in both male and female. Segment VIII (VIII) with large internal gland in male (Fig. 3C), slightly shorter than segment VII (VII), lacking in female.

Male genitalia (Figs 3D-3G). Segment IX longitudinally short in lateral aspect (Fig. 3D), anterior margins angled $50^{\circ}$ in lateral aspect. Segment X (X) triangular in lateral aspect (Fig. 3D), with pair of mesocaudal lobes (m.c.1.) V-shaped in dorsal aspect (Fig. 3E); pair of lateral lobes (1.1) rectangular in dorsal aspect (Fig. 3E), each with apex directed dorsad and with short setae ventrally (Fig. 3D); preanal appendages indistinct, forming only large setose areas. Inferior appendages each with basal segment long club-like, extending beyond apex of segment X (Fig. 3D); distal segment slightly shorter than $1 / 3$ of basal segment, tapering to apex, weakly curved mesad (Fig. 3E). Phallic apparatus thick basally and with apical $2 / 3$ almost straight in lateral aspect (3F), thick apex with two pairs of endothecal processes dorsally, each apex somewhat sharp (Fig. 3F).

Female genitalia (Figs 3H-3J). Sternum VIII cleft from base, lateral lobes (1.1.) widely separated from each other posteriorly in ventral aspect (Fig. 3J). Segment IX (IX) semicircular in dorsal aspect (Fig. 3I), anterior margins gently convex anteriorly about $1 / 3$ from base in lateral aspect (Fig. $3 \mathrm{H})$; with pair of shallow slits posterodorsally; pair of short external sclerotized ribs (s.r.) ventrally (Figs 3H, 3J). Vulval scale (v.s.) with pair of short protrusions basolaterally in ventral aspect (marked with arrow in Fig. 3J), apical part broadly membranous. Segment X (X) rhomboid in lateral aspect (Fig. $3 \mathrm{H})$.

Immature stage. Morphology and biology of this species will be reported in a future work.

Specimens examined. Holotype: Male (in alcohol, M-8232), Ai (200 m), Nita-gun, Shimane, 22.vii.1985, M. Kobayashi (KPM-NK). Honshu, Akita: 2 males, Sashimaki, Tazawa-ko, Semboku-shi, 29.vi.2012, M. Tanaka. Ibaraki: 3 males, Uwaso, Ishioka-shi, 7.vi.2008, N. Katsuma; 1 female, same locality, 15.vii. 2008, N. Katsuma; 5 males, 4 females, same locality, 4.vi.2011, N. Katsuma; 6 males, 5 female, same locality, 11.vi.2011, N. Katsuma. Aichi: 2 males, Hashigoda, Kikko, Moriyama-ku, Nagoya-shi, 16.v.2011, T. Nozaki. Mie: 1 male, Tabika, Komono-cho, alt. 85 m, 1-8.x.2000, H. Morita; 4 males, 1 female, same locality, 6.v.2006, H. Morita; 2 males, same locality, 31.v.2011, H. Morita; 3 males, 4 females, Okubano, Iga-shi, 9-22.vi.2012, H. Morita (NK). Shiga: 1 male, Shishitobi-bashi, Seta-gawa, Oishi-higashi, Otsu-shi, 2.ix.2014, S. Kobayashi. Okayama: 1 male, Okutsu-kawani- 
shi, Kagamino-cho, 26.vi.2013, K. Nojima (KN). Kyushu, Saga: 1 male, Fuji-cho, Saga-shi, 6.v.2011, T. Iwai et al.

Distribution. Japan: Honshu, Kyushu.

Japanese name. Ai-shima-tobikera.
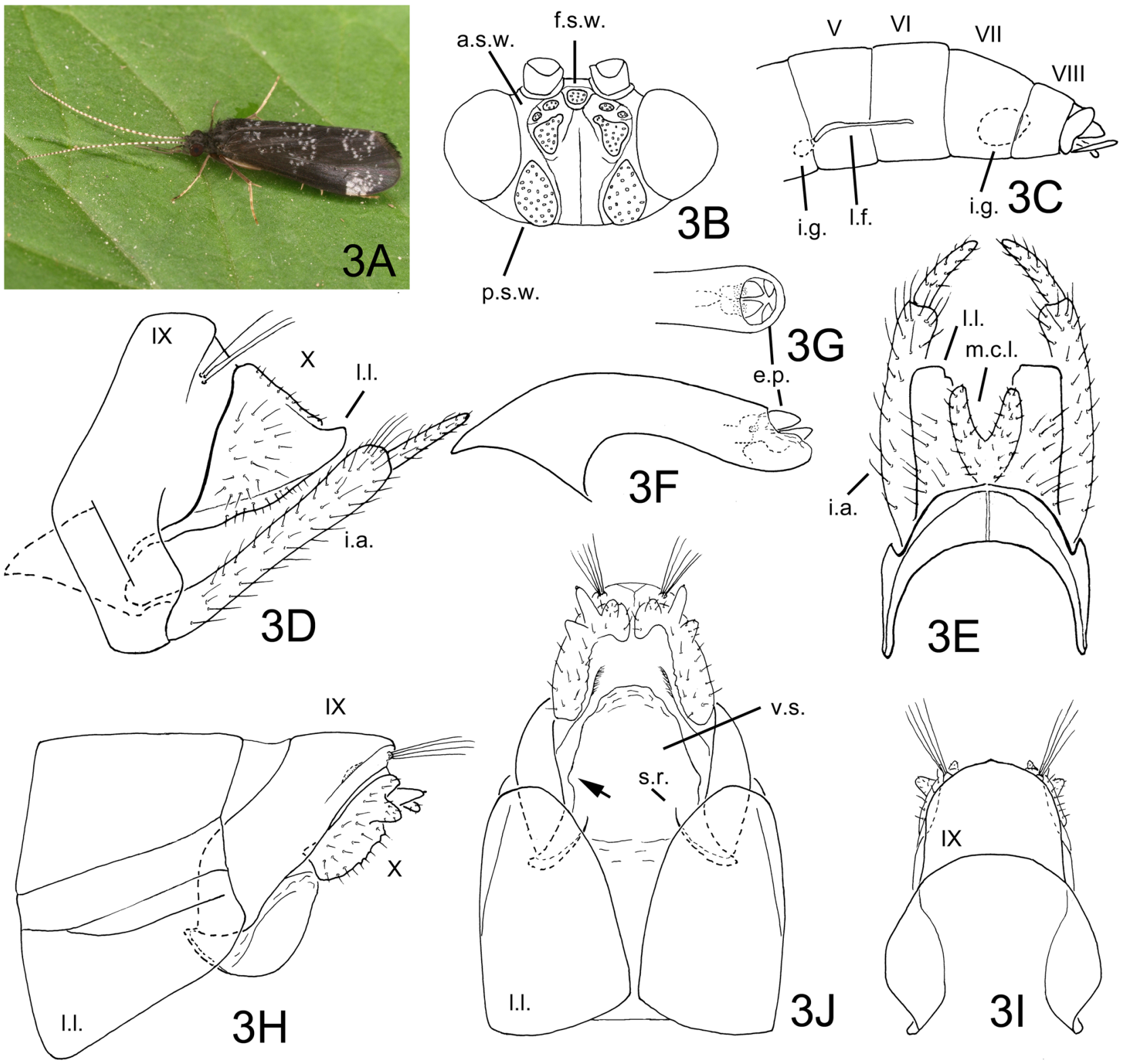

FIGURE 3. Diplectrona aiensis Kobayashi 1987.3A-3G, male: 3A, habitus (Aichi), left lateral; 3B, head, dorsal; 3C, abdominal segments V-X, left lateral; 3D, genitalia, left lateral; 3E, same, dorsal; 3F, phallic apparatus, left lateral; 3G, same, apical part, dorsal. 3H-3J, female genitalia: 3H, left lateral; 3I, dorsal; 3J, ventral. Abbreviations: a.s.w. = anterior setal wart (paired), e.p. $=$ endothecal process (paired), f.s.w. $=$ frontal setal wart, i.a. $=$ inferior appendage (paired), i.g. $=$ internal gland (paired) of segment V or VIII, m.c.l. = mesocaudal lobe of segment X (paired), 1.f. = lateral filament (paired), 1.1. = lateral lobe of segment VIII in female or X in male (paired), p.s.w. = posterior setal wart (paired), s.r. = sclerotized rib (paired), V-X=abdominal segments V-X, v.s. = vulval scale. Arrow: see text.

\section{Diplectrona takaii sp. nov.}

(Figs 4, 7)

Diplectrona sp. DC: Akagi 1956, 24-25, larva; Kagaya et al. 1998, 47.

Diplectrona sp. 1: Torii \& Hattori 2006, 37.

Diplectrona sp. (aiensis gr.): Kawase \& Morita 2010, 42. 
Diplectrona sp. (aff. aiensis): Nojima 2017, 119.

Diplectrona sp.: Nozaki 2016, 75, 348, photo (adult male)
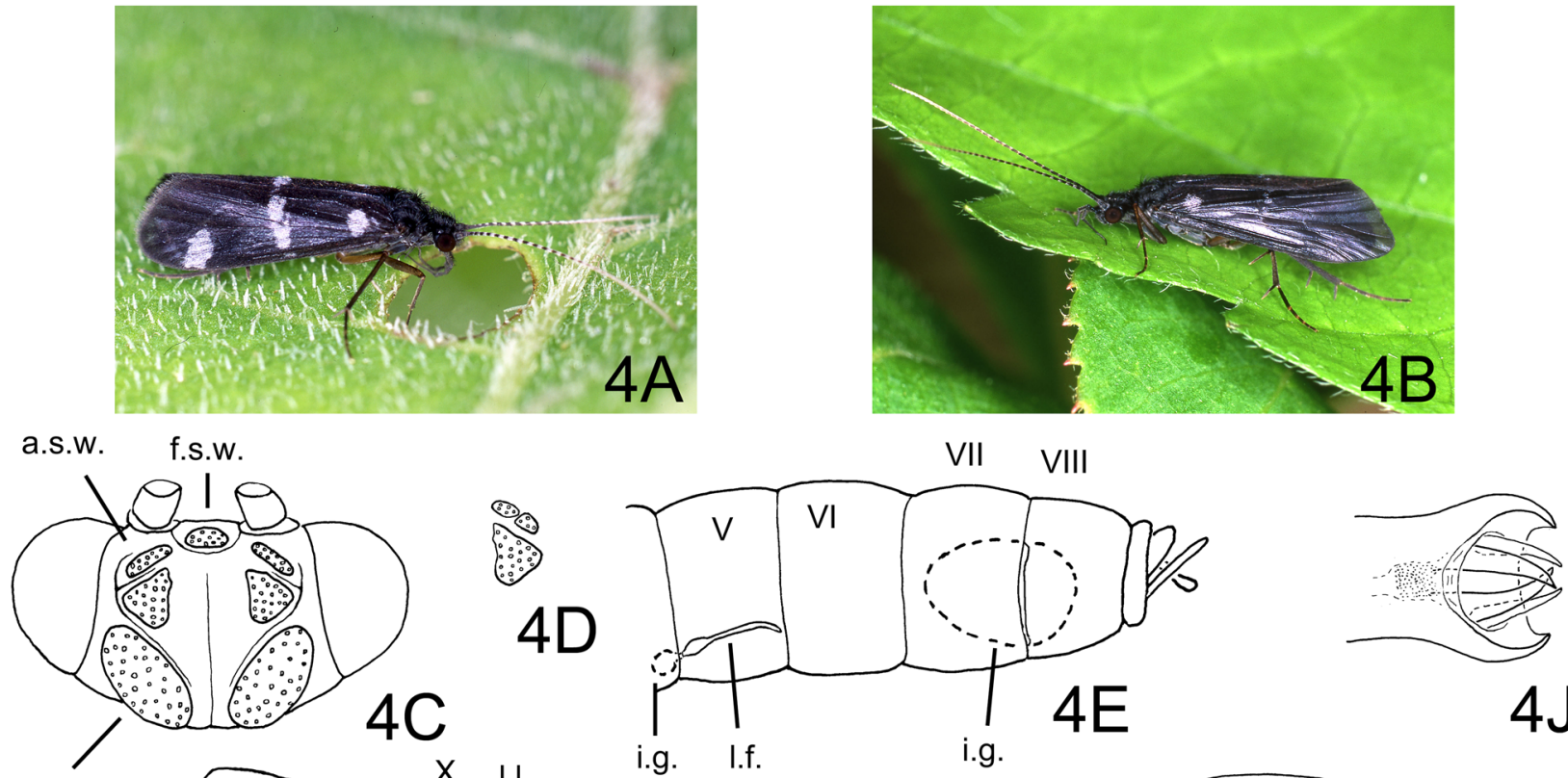

p.s.w,

i.g. I.f.

i.g.

4J
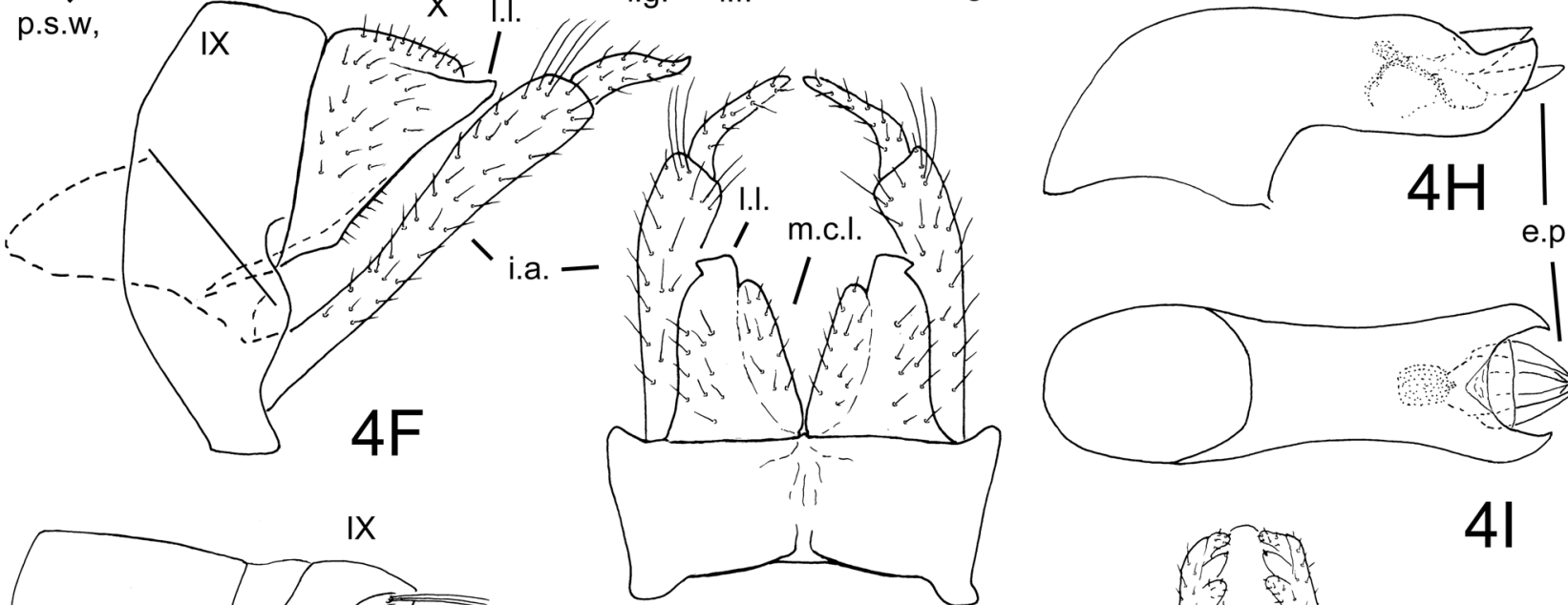

e.p.
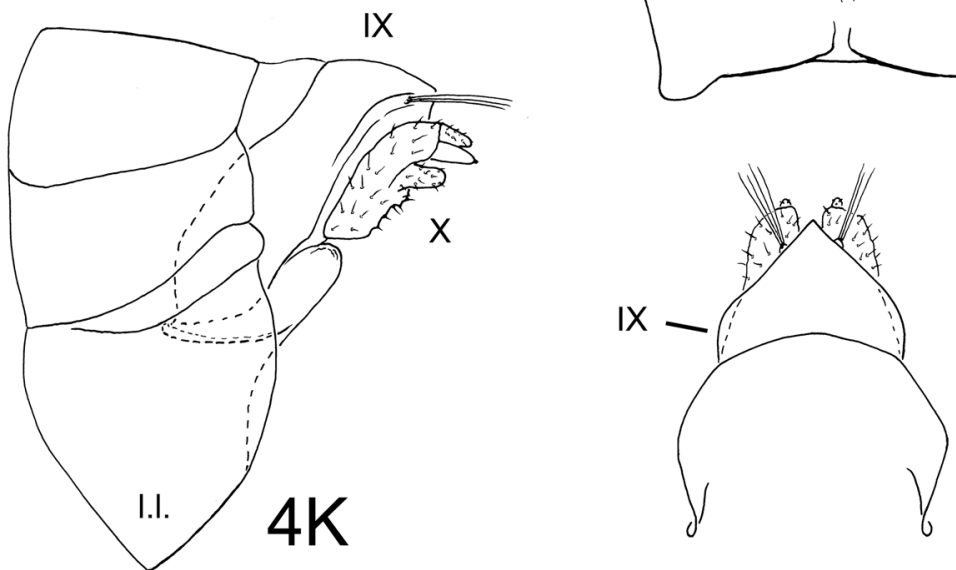

$4 G$

FIGURE 4. Diplectrona takaii sp. nov. 4A-4J, male: 4A, habitus (Holotype, Kochi, photographed by M. Takai), right lateral; 4B, same, variation (Kochi, photographed by M. Takai), left lateral; 4C, head, dorsal; 4D, right anterior setal wart, variation, dorsal; 4E, abdominal segments V-X, left lateral; 4F, genitalia, left lateral; 4G, same, dorsal; 4H, phallic apparatus, left lateral; 4I, same, ventral; 4J, same, apical part, dorsal. 4K-4M, female genitalia: 4K, left lateral; 4L, dorsal; 4M, ventral. Abbreviations: a.s.w. = anterior setal wart (paired), e.p. $=$ endothecal process (paired), f.s.w. $=$ frontal setal wart, i.a. $=$ inferior appendage (paired), i.g. = internal gland (paired) of segment V or VIII, m.c.l. = mesocaudal lobe of segment X (paired), 1.f. = lateral filament (paired), 1.1. = lateral lobe of segment VIII in female or X in male (paired), p.s.w. = posterior setal wart (paired), s.r. = sclerotized rib (paired), $\mathrm{V}-\mathrm{X}=$ abdominal segments $\mathrm{V}-\mathrm{X}$, v.s. = vulval scale. 
Diagnosis. The male of this species is similar to that of D. albofasciata known from Taiwan and the southernmost islands of Japan, and Diplectrona wangyipingi Sun 2017, described from China. However, the male is easily distinguishable from the latter two species by the shape of the phallotheca: the phallotheca bears a pair of prominent apicolateral lobes in this species, but it lacks such lobes in D. albofasciata and D. wangyipingi. Furthermore, the length of the internal gland is longer than segment VII in this species, but shorter than the segment in D. albofasciata and $D$. wangyipingi; and the length of the lateral filaments is approximately the same length as segment $\mathrm{V}$ in this species, but longer than the segment in $D$. wangyipingi.

Adult (Figs 4A-4M). Head and body (Figs 4A, 4B) mostly dark brown; antennae with dark stripes, but apical half paler. Forewings dark brown to black with white markings, but markings variable: on Shikoku usually with 3 large white markings (Fig. 4A), but occasionally indistinct (4B); on Honshu with sparse white spots similar to those on D. kibuneana (Fig. 1A). On head, frontal setal wart (f.s.w.) small oval, each anterior setal wart (a.s.w.) divided into 2 warts (Fig. 4C), anterior one long oval but often divided into 2 small warts (Fig. 4D), posterior one triangular; each posterior setal wart (p.s.w.) large oval. Forewings each 5.0-7.2 mm long in male $(\mathrm{n}=10), 5.5-8.2 \mathrm{~mm}$ in female ( $\mathrm{n}=10)$, venation similar to that of D. kibuneana (Fig. 1C). Pair of lateral filaments (1.f.) of abdominal segment $\mathrm{V}(\mathrm{V})$ short, each approximately same length as segment $\mathrm{V}$ in both male and female (Fig. 4E). Segment $\mathrm{V}$ with small internal gland (i.g.) in both male and female (Fig. 4E). Segment VIII (VIII) with internal gland in male, very large, longer than segment VII (VII) (Fig. 4E), lacking in female.

Male genitalia (Figs 4F-4J). Segment IX (IX) in lateral aspect (Fig. 4F) narrow, anterior margins gently convex anterad, posterior margins sinuate in ventral half. Segment X (X) triangular in lateral aspect (Fig. 4F); pair of mesocaudal lobes (m.c.l.) V-shaped in dorsal aspect (Fig. 4G), laterally fused with respective lateral lobe; pair of lateral lobes (1.1.) protruding caudad posterodorsally, apically triangular and with short setae posteroventrally in lateral aspect (Fig. 4F), truncate in dorsal aspect (Fig. 4G); preanal appendages indistinct, only forming pair of large setose areas. Inferior appendages (i.a.) each with basal segment long club-like, apical 1/3 slightly thicker, extending beyond apex of segment X (X) (Fig. 4F); distal segment about 1/3 as long as basal segment, tapering to apex, weakly curved mesad (Fig. 4G). Phallic apparatus short and thick; bilobed apically in dorsal and ventral aspects (Figs 4I, 4J), each lateral lobe triangular in lateral aspect (Fig. 4H), its apex directed dorsomesad (Fig. 4H, 4J); with two pairs of long endothecal processes (e.p.) apicodorsally, each process lanceolate, ventral processes narrower than dorsal processes (Figs $4 \mathrm{H})$.

Female genitalia (4K-4M). Sternum VIII cleft from base, each lateral lobe (1.1.) quarter-circle in ventral aspect (Fig. 4M). Segment IX (IX) almost rhomboid in lateral aspect (Fig. 4K), triangular posteriorly in dorsal aspect (Fig. 4L), anterior margin slightly convex anteriorly about $1 / 3$ from base in lateral aspect; with pair of external sclerotized ribs (s.r.) ventrolaterally (Fig. 4M). Vulval scale (v.s.) tongue-like in ventral aspect (Fig. 4M), membranous apically. Segment X (X) rhomboid in lateral aspect (Fig. 4K).

Immature stages. Diplectrona sp. DC described by Akagi (1956) is the larval stage of this species. The adult and larval association of this species was established by Kagaya et al. (1998).

Holotype. Male (in alcohol), Mt. Iwaguro, Teragawa, Ino-cho, Kochi, $33.744^{\circ} \mathrm{N}, 133.162^{\circ} \mathrm{E}$, alt. ca. $1350 \mathrm{~m}$, 17.vii.2004, M. Takai (CBM-ZI 0180241).

Paratypes. 24 males, 2 females, Namakusa-dani, Odamiyama, Nakagawa, Uchiko-cho, Ehime, $33.562^{\circ} \mathrm{N}$, $132.916^{\circ} \mathrm{E}$, alt. $1200 \mathrm{~m}, 8$.vii.2000, E. Yamamoto (CBM-ZI 0180244-0180269); 10 males, 5 females, same locality, 24.vii.2000, E. Yamamoto (KPM-NK); 1 male, 1 female, Yosakoi-toge, Teragawa, Ino-cho, Kochi, 3.viii.2001, I. Yamashita (CBM-ZI 0180242-0180243).

Other specimens examined. Honshu, Tokyo: 2 males, Hirai-gawa, Hinode-machi, larvae collected on 20.vii.1990, adults emerged on 10-15.viii.1990, by T. Nozaki. Shizuoka: 1 female, Oyamada-gawa, Horikiri, Izushi, alt. 350 m, 14.v.1995, T. Hattori (SPMN-IS); 1 female, Yokosawa, Aoi-ku, Shizuoka-shi, alt. 550 m, 8.vi.2001, T. Hattori (SPMN-IS); 1 male, same locality, 18.v.2005, T. Hattori (SPMN-IS); 1 male, Utoge-no-taki, Kurata, Fujieda-shi, G. Yoshinari (TT). Gifu: Ten-no-taki, Mikawa, Shirakawa-cho, 12.vi.2010, T. Nozaki. Shiga: 11 males, 4 females, Yuzurio, Eigenji, Higashi-Omi-shi, 31.v-26.vi.2009, N. Kawase (NK); 11 males, 40 females, same locality, 26.vi-29.vii.2009, N. Kawase (MITR-20090429 \& 20090433). Okayama: 1 male, 1 female, Ogaya, Nishiawakurason, 15.vii.2017, K. Nojima (KN). Shikoku, Ehime: 1 male, Honomata, Odamiyama, Nakagawa, Uchiko-cho, 21-30.vi.2000, E. Yamamoto (TN); 1 male, 1 female, Ishizuchi Sky-line, Kumakogen-cho, 3.viii.2006, M. Takai. Kochi: 1 female, Teragawa, Ino-cho, 16.vii.2000, I. Yamashita; 1 male, Befu-kyo, Monobe, Kami-shi, 16.v.2003, M. Takai; 1 female, Shiragagoe, Monobe-cho, Kami-shi, 3.vii.2004, M. Takai; 1 male, 1 female, Mt. Shiraga, Monobe, Kami-shi, Kochi, 25.vii.2004, M. Takai. 
Etymology. This species is dedicated to Mr. Mikio Takai, who provided me valuable specimens and excellent photographs, including specimens and photographs of this species.

Distribution. Japan: Honshu, Shikoku.

Japanese name. Takai-miyama-shima-tobikera.

Remarks. The markings of the forewings in this species are variable, and Malicky (2002) also reported similar variations in D. albofasciata.

\section{Species wrongly assigned to the genus Diplectrona}

\section{Homoplectra japonica (Banks 1906), New combination.}

(Fig. 5)

Arctopsyche japonica Banks 1906, 111, 113, color pattern of forewing.

Specimens examined. Kyushu, Fukuoka: 11 males, Mt. Hiko-san, Soeda-machi, 19.v.1993, N. Kuhara (KuN).

Remarks. Banks (1906) described Arctopsyche japonica based on specimens collected from Hikosan, Buzen (now Fukuoka, Kyushu), and a figure of distinct yellow markings of the left forewing was provided. He also recorded this species from Gifu, central Honshu, but precise data were not provided (Banks 1906). Ulmer (1907) transferred this species to the genus Diplectrona based on examination of males collected from Gifu, which have similar markings to the illustration by Banks (1906). However, according to photographs of a syntype male collected from Hikosan, and deposited in the Museum of Comparative Zoology, Harvard University (Figs 5A-5D: photographed by C. W. Farnum), the male bears a club-like process on each anterolateral corner of abdominal sternum V (s.V) (marked with an arrow in Fig. 5B). Furthermore, in male genitalia (Fig. 5C), each inferior appendage (i.a.) is onesegmented, and the large phallic apparatus (ph.) bears long spine-like processes. Males collected from the same area as the syntype male was collected have the same genitalic morphology (Fig. 5E). This species therefore belongs to the genus Homoplectra, and not to Diplectrona.

After the publication by Banks (1906), many authors recorded D. japonica based on the characteristic markings of the forewings; however, Kawase \& Morita (2014) noted that multiple species have this character. This taxonomic problem warrants future work.

\section{Homoplectra albomarginata (UImer 1907), New combination.}

(Fig. 6)

Diplectrona albomarginata Ulmer 1907, 74.

Specimens examined. Honshu, Gifu: 1 female, Ozu, Ibigawa-cho, 14-16.v.2001, N. Kawase (NK); 1 female, Nishimaenotani, Tsurumi, Ibigawa-cho, 10.iv.2002, N. Kawase (NK). Shiga: 45 females, Yuzurio, Eigenji, HigashiOmi-shi, 12-31.v.2009, N. Kawase, by Malaise trap (MITR20090430).

Remarks. Ulmer (1907) described this species as a member of the genus Diplectrona based on a female specimen collected from an unknown locality in Gifu, central Honshu, and provided only a general description without illustrations. In 2021, I obtained photographs of the holotype of this species deposited in the Royal Belgian Institute of Natural Sciences, Brussels (Figs 6A-6D: photographed by J. Lalanne). Although the specimen lacks her head, her abdomen retains the following characteristics: Abdominal sternum V (s.V) bears a club-like process near the anterolateral margin (marked with an arrow in Fig. 6B), the vulvar scale (v.s.) bears a pair of plate-like lobes basally (marked with a black arrow in Fig. 6C), and a large pocket-like concavity between segment IX and vulval scale (marked with a white arrow in Fig. 6C). Through the course of my study, I obtained females collected in Gifu, which have these characters (the latter two characters marked with arrows in Fig. 6E). Their morphology, such as stout antennae, shape of wings, wing venation, etc., suggests that this species does not belong to the genus Diplectrona, but to Homoplectra. Although the markings of the forewings of the holotype female are indistinct (Fig. 6A), the two females examined in this study have forewings with distinct yellow markings similar to those of $H$. japonica. 

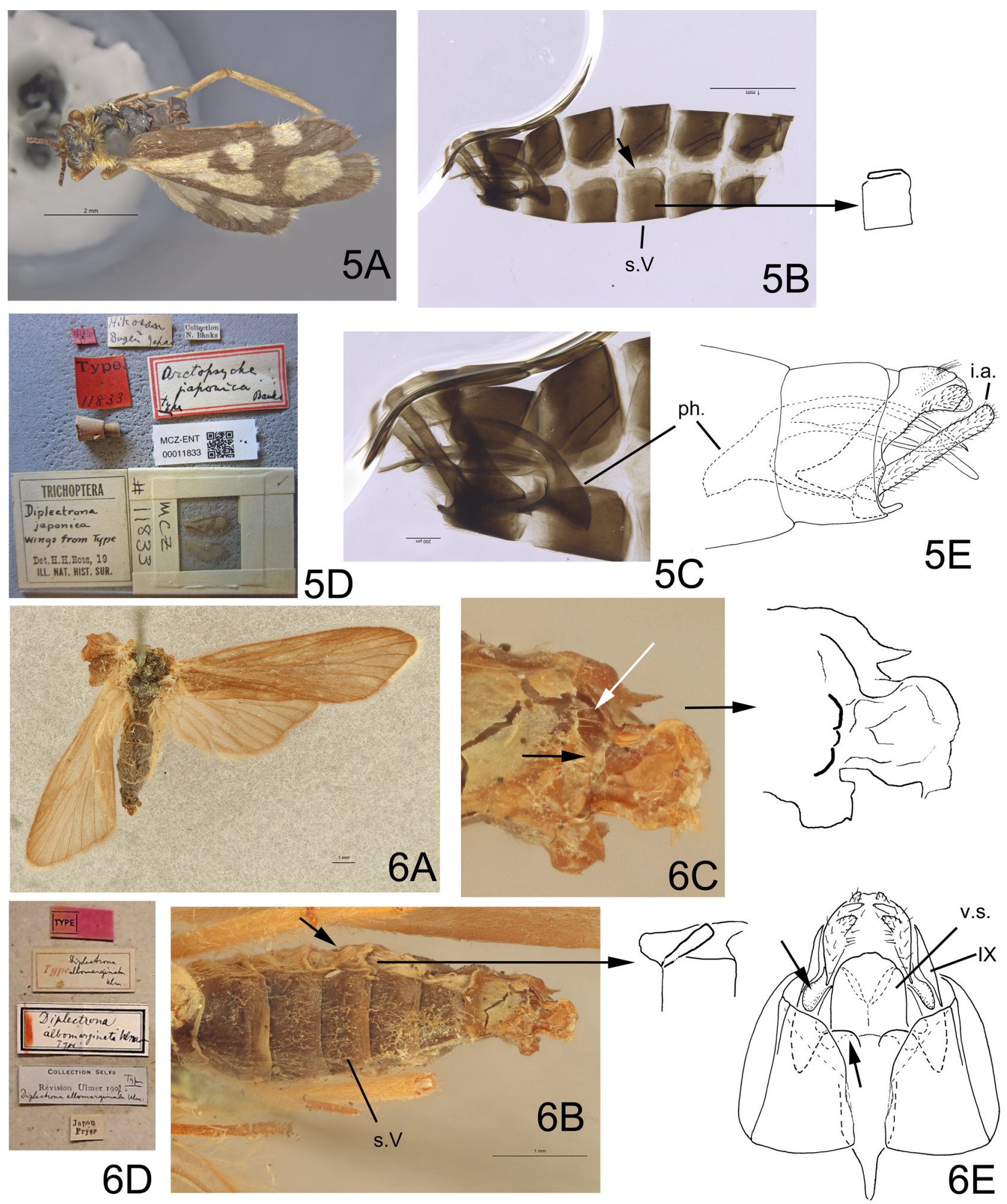

FIGURES 5-6. 5A-5E, Homoplectra japonica (Banks 1906). 5A-5D, syntype male (MCZ-ENT00011833, Museum of Comparative Zoology, Harvard University, photographed by C.W. Farnum): 5A, dorsal; 5B, abdomen, right lateral, sternum V traced outline; 5C, genitalia, right lateral; 5D, labels. 5E, male genitalia (Mt. Hiko-san, Fukuoka), left lateral. 6A-6E, Homoplectra albomarginata (Ulmer 1907). 6A-6D, holotype female (Royal Belgian Institute of Natural Sciences, photographed by J. Lalanne): 6A, dorsal; 6B, abdomen, ventral, left lateral part of segment $\mathrm{V}$ traced outline; $6 \mathrm{C}$, genitalia, ventral, apical part traced outline; 6D, labels. 6E, female genitalia (Gifu), ventral. Abbreviations: i.a. = inferior appendage, IX = abdominal segment IX, ph. = phallic apparatus, s.V = abdominal sternum V, v.s. = vulval scale. Arrows: see text. 
Furthermore, 45 females collected from Shiga, an adjacent district of Gifu, have the same genitalic morphology as the holotype and 36 of these females bear the distinct markings, but 9 of them lack the markings. Redescription of this species in detail, including the variation of wing coloration, warrants future study.

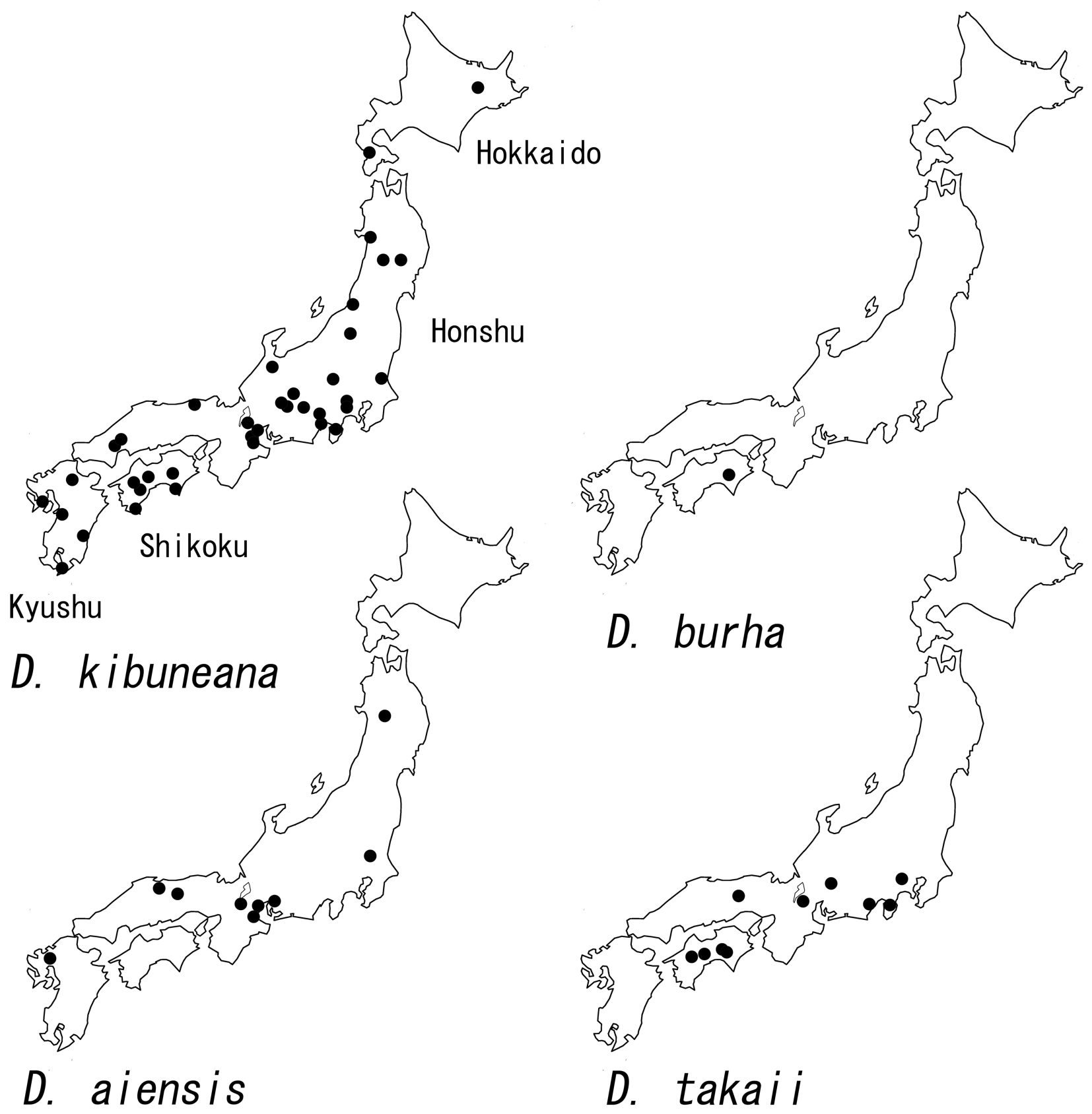

FIGURE 7. Distribution of Diplectrona species on the Japanese main islands.

\section{Acknowledgements}

I am sincerely grateful to Drs Crystal Maier and Charles W. Farnum, Museum of Comparative Zoology, Harvard University; and to Drs Jérôme Constant and Julien Lalanne, Royal Belgian Institute of Natural Sciences, Brussels, for providing fine photographs of the types of Arctopsyche japonica and Diplectrona albomarginata, respectively. I am also grateful to Drs John, C. Morse, Clemson University, and Wolfram Mey, Potsdam, for their cooperation to obtain those photographs. My deep thanks are due to Dr Kyohei Watanabe, Kanagawa Prefectural Museum of Natural History, Odawara, for the loan of the type specimens of Hydropsyche difficultata and Diplectrona aiensis. For the loan or the gift of valuable materials, and/or guidance for field collections, I am grateful to the following 
persons: Mr Hiroaki Iketake, Nagoya-shi, Mr Shu Inaba, Shimoda-shi; Dr Tomiko Ito, Hokkaido Aquatic Biology, Eniwa-shi; Mr Nobuyuki Katsuma, Ushiku-shi; Mr Naoki Kawase, Minakuchi Kodomo-no-mori Nature Center, Koka-shi; Dr Toshio Kishimoto, Museum of Natural and Environmental History, Shizuoka-shi; Dr Naotoshi, Kuhara, Chitose-shi; Mr Hisayuki Morita, Yokkaichi-shi; Ms Kaori, Nio, Kochi-shi; Mr Koichi Nojima, Okayama-shi, Mr Mikio Takai, Kami-shi; Mr Masayuki Tanaka, Akita-shi; Mr Takaaki Torii, University of Shizuoka, Shizuokashi; and Mr Eiji Yamamoto, Uchiko-cho. Mr M. Takai also provided fine photographs of D. kibuneana, D. burha, and D. takaii sp. nov. Finally, I am also very grateful to Dr Kazumi Tanida, an anonymous reviewer, and the editor, Dr John C. Morse for their valuable suggestions and comments to improve the manuscript.

\section{References}

Akagi, I. (1956) Miyama-shima-tobikera-zoku yochu no kenkyu [Larvae of the genus Diplectrona]. Kansai Shizenkagaku Kenkyu-kai Kaishi, 9, 23-25. [in Japanese]

Banks, N. (1906) New Trichoptera from Japan. Proceedings of the Entomological Society of Washington, 7, 106-113.

Griffin, F.J. (1932) On the dates of publication of the parts of Westwood (J.O.), Introduction to the modern classification of insects, 1838-1840. Proceedings of the Royal Entomological Society of London (A), 6 (3), 83-84.

Inazu, K. \& Nishida, A. (2011) Trichoptera. In: Editorial office of Hyogo Fresh Water Biology (Ed.), Hyogo no kawa no ikimono zukan. Hyogo Rikusui-seibutsu Kenkyu-kai, Himeji, pp. 169-212. [in Japanese]

Ito, T. \& Nozaki, T. (2018) The family Hydropsychidae Curtis (Trichoptera) in the Ryukyu Archipelago, southwestern Japan. Zootaxa, 4504 (4), 545-565. https://doi.org/10.11646/zootaxa.4504.4.6

Kagaya, T., Nozaki, T. \& Kuranishi, R.B. (1998) Fauna and distribution of Trichoptera in the Tama-River system. In: Katagiri, K. (Ed.), Fauna and Distribution of Trichoptera, in the Tama-River System. Tokyu Foundation for Better Environment, Tokyo, pp. 1-266. [in Japanese]

Kawase, N. \& Morita, H. (2010) The caddisfly (Insecta, Trichoptera) fauna of the Suzuka Mountains. Biology of Inland Waters, 25, 31-40. [in Japanese with English abstract]

Kawase, N. \& Morita, H. (2014) The caddisfly (Insecta: Trichoptera) fauna of the upstream area of the Takatori River, Shiga Prefecture, central Japan. Biology of Inland Waters, 28, 1-10. [in Japanese with English abstract]

Kobayashi, M. (1973) Caddisfly fauna of the vicinity of Yamagata Prefecture, with descriptions of thirteen new species. Bulletin of the Kanagawa Prefectural Museum (Natural Science), 6, 21-43, pls. 3-10.

Kobayashi, M. (1984) Descriptions of several species of Trichoptera from central Japan (Insecta). Bulletin of the Kanagawa Prefectural Museum (Natural Science), 15, 1-14.

Kobayashi, M. (1987) Caddisflies or Trichoptera from Shimane Prefecture in Japan (Insecta). Bulletin of the Kanagawa prefectural Museum (Natural Science), 17, 13-35.

Malicky, H. (2002) Ein Beitrag zur Kenntnis asiatischer Arten der Gattung Diplectrona Westwood 1840 (Trichoptera,Hydropsy chidae) (gleichzeitig Arbeit Nr. 34 über thailändische Köcherfliegen). Linzer Biologische Beiträge, 34 (2), 1201-1236.

Malicky, H. (2020) Beitäge zur Kenntnis chinesischer Köcherfliegen (Insecta, Trichoptera). Linzer Biologische Beiträge, 52 (1), 417-455.

Malicky, H. \& Mey, W. (2020) Beschreibung von 29 neuen Köcherfliegen-Arten (Trichoptera) aus Myanmar. Zeitschrift der Arbeitsgemeinschaft Österreichischer Entomologen, 72, 49-72.

McLachlan, R. (1868) Contribution to the knowledge of European Trichoptera. Transactions of the Entomological Society of London, 1868, 289-308. https://doi.org/10.1111/j.1365-2311.1868.tb00629.x

Morita, H. (2013) Aoyama-kogen no tobikera-so. Hirakura, 57 (3), 60-64. [in Japanese]

Morse, J.C. (2021) Trichoptera World Checklist. Available from: http://entweb.clemson.edu/database/trichopt/index.htm (accessed 17 October 2021)

Nojima, K. (2017) Caddisflies (Insecta: Trichoptera) in Okayama Prefecture, western Japan. Biology of Inland Waters, 32, 107-131. [in Japanese with English abstract]

Nozaki, T. (1997) Trichoptera. In Kanagawa Park Association and the Plan Committee, General Investigating Group of Tanzawa Oyama Natural Environments (Ed.) Tanzawa-sanchi Doshokubutsu Mokuroku [List of fauna and flora of Tanzawa mountains]. Kanagawa Prefectural Government, Yokohama, pp. 31-38. [in Japanese]

Nozaki, T. (2016) Trichoptera. In: Maruyama, H. \& Hanada, S. (Ed.), A Field Guide to Japanese Aquatic Insects: Adults of Mayflies, Stoneflies and Caddisflies. Zenkoku Noson Kyoiku Kyokai, Tokyo, pp. 69-87+294-410. [in Japanese]

Nozaki, T. (2019) Descriptions of five new species of Homoplectra Ross (Trichoptera, Hydropsychidae) from Japan with reassignment of Homoplectra tohokuensis (Kobayashi). Zootaxa, 4608 (2), 329-344. https://doi.org/10.11646/zootaxa.4608.2.7

Oláh, J. \& Johanson, K.A. (2008) Reasoning an appendicular and functional caddisfly genital terminology. Braueria, 35, 2940. 
Oláh, J., Oláh, J. Jr. \& Li, W-h., (2020) On the Trichoptera of China with relatives of adjacent territories I. Opuscula Zoologica, Budapest, 51 (2), 153-212. https://doi.org/10.18348/opzool.2020.2.153

Park, S-j., Inaba, S., Nozaki, T. and Kong, D. (2017) One new species and four new records of caddisflies (Insecta: Trichoptera) from the Korean Peninsula. Animal Systematics, Evolution and Diversity, 33 (1), 1-7. https://doi.org/10.5635/ASED.2017.33.1.032

Ross, H.H. (1938) Descriptions of new North American Trichoptera. Proceedings of the Entomological Society of Washington, $40(5), 117-124$

Schmid, F. (1961) Trichoptères du Pakistan. 4me partie (fin). Tijdschrift voor Entomologie, 104, 187-230, pls. $13-25$.

Schmid, F. (1998) The Insects and Arachnids of Canada, Part 7. Genera of the Trichoptera of Canada and Adjoining or Adjacent United States. NRC Research Press, Ottawa, 319 pp.

Sun, C-h. (2017) Eight new species of Diplectrona (Trichoptera: Hydropsychidae) from China. Journal of the Kansas Entomological Society, 90 (2), 146-161. https://doi.org/10.2317/0022-8567-90.2.146

Tanaka, M. (2016) Akita-ken no tobikera-moku bunpushiryo 7 [Caddisflies of Akita Prefecture 7]. Akita Nature Study, 70, 1-5. [in Japanese]

Tanida, K. (1985) Trichoptera. In: Kawai, T. (Ed.), An Illustrated Book of Aquatic Insects of Japan. Tokai University Press, Tokyo pp. 167-215. [in Japanese]

Tanida, K. (2018) Hydropsychidae. In: Kawai, T. \& Tanida, K. (Eds.), Aquatic Insects of Japan: Manual with Keys and Illustrations, 2nd edition. Tokai University Press, Hiratsuka, Kanagawa, pp. 567-583. [in Japanese]

Torii, H. \& Hattori, T. (2006) Trichoptera fauna of the Seto River system, Shizuoka, central Japan. Biology of Inland Waters, 21, 3141. [in Japanese with English abstract]

Tsuda, M. (1940) Zur Kenntnis der Japanischen Hydropsychiden (Trichoptera). Annotationes Zoologicae Japonenses, 19 (1), 23-34.

Tsuda, M. \& Akagi, I. (1962) Trichoptera. In: Tsuda, M. (Ed.), Aquatic Entomology. Hokuryukan, Tokyo, pp. 112-148. [in Japanese]

Ulmer, G. (1907) Trichopteren. Part. 1. Collection Zoologiques du Baron Edm. de Selys Longchamps, 6 (1), 1-102.

Ulmer, G. (1913) H. Sauter's Formosa-Ausbeute. Trichopteren. Entomologische Mitteilungen, 2 (2), 48-50. https://doi.org/10.5962/bhl.part.14989

Wells, A. \& Neboiss, A. (2018) Australian Diplectroninae reviewed (Insecta: Trichoptera), with description of 21 new species, most referred to a new genus. Zootaxa, 4415 (1), 1-44. https://doi.org/10.11646/zootaxa.4415.1.1

Westwood, J.O. (1839) An Introduction to the Modern Classification of Insects, Founded on the Natural Habits and Corresponding Organisation of the Different Families and Synopsis of the Genera of British Insects. 2 (9-16) \& sheets E-L except J ["1839-1840”]. A. Spottiswoode, London, xi + 587 pp. \& 158 pp. [published in parts (Griffin 1932; Wells \& Neboiss 2018)] 